\title{
Design and Research of Mobile Learning Platform from the Perspective of Flipped Classroom
}

\author{
Chao Chen ${ }^{1, a}$ and Lishuang Zhao ${ }^{1, b}$ \\ ${ }^{1}$ College of Information Science and Technology, Bohai University, Jinzhou 121013, China \\ achch56@126.com, bbhdxzls@126.com
}

Keywords: Mobile learning; Flipped classroom; Teaching model innovation; Mobile learning platform

\begin{abstract}
With the rapid development of educational philosophy and educational technology, the Flipped Classroom has been typical model of teaching mode innovation in the 21 st century. But limited classroom time cannot meet the needs of students' learning and teachers' teaching. The mobile learning terminal and the digital learning platform can provide powerful support for the learning environment for students at anytime and anywhere. This paper introduces the concept of flipped classroom and mobile learning, and introduces the features of mobile learning in flipped classroom. And further explores the rationality and effectiveness of mobile resource design. Finally, the learning platform in flipped classroom is discussed.
\end{abstract}

\section{Introduction}

The rapid development of information technology provides unlimited possibilities for the innovation of education and teaching. As a typical innovation of learning methods and teaching mode respectively, mobile learning and flipped classroom have been the core of teaching reform in colleges and universities.

The flipped classroom teaching mode which essentially transfers the initiative in curriculum learning from teachers to students, and then recombines the class learning time inside and outside of classroom.Mobile learning can enable students to obtain educational resources through mobile intelligent terminals, make full use of fragmented time to study, and effectively improve the efficiency and quality of learning. Mobile learning platform meets the needs of learners to learn anytime, anywhere.

\section{Flipped Classroom and Mobile Learning}

Flipped Classroom. Flipped classroom teaching mode is a kind of new, effective and popular mode at present. Its appearance is an inevitable outcome of the digital age.[1] The so-called flipped classroom is a kind of teaching pattern in which students learn their course autonomously through the digital materials (audio and video, e-textbook etc.) distributed by teachers before class, participate in the interactive activities (answering question, solving problems, inquiring etc) of peers and teachers and finish the exercise during the classroom.

The flipped classroom teaching mode has subverted the traditional teaching mode in which the transfer of knowledge is the homework to be done before class. Knowledge acquisition is based on assigned readings, podcasts, or course videos. Teachers as mentors guide students to a higher level of learning and memory retention during flipped classroom teaching. The desired results of this model is to enable students to achieve a higher level of learning and participation, to optimize the teachers' teaching hours and to expand the learning goals to areas beyond knowledge (such as professionalism, communication skills, critical thinking, etc). [2-4]The most important thing is that when students try to use the acquired knowledge in real life, they will have the opportunity to get expert guidance and help from their peers. 
Mobile learning. Mobile learning, known as E-Learning abroad, is a new way of learning accompanied by the update of information technology and continuous upgrade.[5]

The definition of national colleges and universities education technical cooperation committee is "Mobile learning is based on the wireless mobile networks, internet and multimedia technology, teachers and students implement interactive teaching activities conveniently and flexibly through the use of wireless devices (such as mobile phone, iPad, notebook computer) as well as information exchange in education, science and technology."

Mobile learning has the unique advantages what traditional teaching does not have: [6-8]

1) Mobility of learning style. Learners can experience the joy of the mobile learning process by carrying the mobile learning device, as long as they are in the wireless network environment.

2) Effectiveness and randomness of the learning process. Learners can quickly access to learning resources, ask questions to teachers or to prompt students, also can get their reply in time during the process of learning. They can terminate or not according to the learner's own schedule.

3) Personalization of learning content. Learners arrange their own time and place, select the required content, and according to their own individual situations.

4) The fusion of supportive techniques. Wireless communication technology, multimedia technology, large capacity technology of mobile devices and data access technology provide a full range of support.

Features of mobile learning in flipped classroom. The content of mobile learning in the flipped classroom contains only single thought knowledge units whose content and theme cannot be further divided into smaller. The way of learners acquiring learning content is changing and the learner's position is changing during mobile learning. Moreover, mobile learning is mostly in the fragmentary time.[9-11] As a kind of effective learning choice, mobile learning can effectively help learners to achieve practical learning goals. The specific characteristics are shown in Table 1.

Table 1 Features of mobile learning in flipped classroom

\begin{tabular}{|c|c|}
\hline Feature dimension & description \\
\hline Interactive mode & one-to-one, one-to-many \\
\hline learning environment & mobile communication network \\
\hline accessing methods & WiFi access, 3G access, 4G access \\
\hline learning terminals & mobile phone, iPad, laptop \\
\hline executing platform & cognition, emotion, skill \\
\hline learning goal & short and pithy \\
\hline learning content & general social software, special learning platform \\
\hline learning method & autonomous Learning, cooperative learning \\
\hline learning process & anytime, anywhere, attention highly dispersed \\
\hline learning evaluation & self evaluation \\
\hline
\end{tabular}

\section{The Design for Mobile Learning Resource in Flipped Classroom}

\section{The Design of Content.}

(1) Minimal knowledge Unit.

Mobile learning takes place in spare minutes, learners are in a state of non continuous learning, so it is difficult to complete one time if the learning content includes more knowledge. Therefore, learning content is divided into a minimal knowledge blocks according to the actual situation of granularity of learning content which can facilitate the transfer and sharing of knowledge, and is convenient for learners to carry out learning activities whenever and wherever possibly.

(2) Relatively Loose Organizational Structure. 
Each of the learning content and adjacent learning content can be loosely recombination, showing a continuous implicit structure which can be combined by the way learners choose and builders of preset phase, so that the learners can learn these adjacent learning content under one learning goal.

(3) Relatively Complete Learning Content.

As mobile learning is a kind of non continuous learning, it is necessary to study the content of the self inclusive that is provided by the knowledge unit is relatively complete to ensure that learning can be carried out at any time. Learners use the learning content without the need of additional learning content to achieve the desired learning objectives.

(4) Dynamic Learning Content Design.

Teachers should follow the principle of dynamic in the design of learning content, so that the mobile learning resources builders can add, delete and modify the learning content at any time, so as to ensure the advanced learning content.

(5) Succinct Interactive Interface.

The human-machine interface should be simple and easy to operate to adapt to the micro learning content.

\section{The Design of Media.}

(1) Choosing Appropriate Media.

In the mobile learning platform, we should try to use text, music, pictures, video and other media in the form of appropriate media to present mobile learning content in order to ensure the learning effect of mobile learning.

(2) Choosing Media with Small Flow.

The use of mobile learning platform to show learning resources will consume traffic and generate communication costs. Therefore, under the premise of the same learning effect, we should choose a small flow of media to show the content of mobile learning.

(3) Open-ended Mode of Media Presenting.

If conditions permit, the same content to learn should be presented in a variety of different media, so that learners can choose their favorite mobile media for learning according to their own learning preferences.

\section{The Construction of Mobile Learning Platform in Flipped Classroom}

The Design of Mobile Learning Model in Flipped Classroom. According to the above analysis, we can form the mobile learning teaching model in the flipped classroom as shown in Fig. 1. The mobile learning model is divided into six levels: mobile learning environment, mobile learning device, mobile learning theory, mobile learning resources, mobile learning methods and mobile learning activities. The core of these levels is the learning activity based on the flipped classroom. The whole teaching process is divided into three parts, pre class, in class and after class. And we construct the teaching procedure in sequential order, from pre-class, during-class to post-class, the specific description of each component is as follows. 


\begin{tabular}{|c|c|c|c|}
\hline \multicolumn{4}{|l|}{ M-learning activities } \\
\hline watchlng video & \multicolumn{2}{|c|}{ discusslng the issue } & \multirow{2}{*}{ feedbacking } \\
\hline exchanolno & \multicolumn{2}{|c|}{ conducting experiments } & \\
\hline practicing & \multicolumn{2}{|c|}{$\begin{array}{c}\text { completing exercises and } \\
\text { assignments }\end{array}$} & summarizing \\
\hline Before class & \multicolumn{2}{|c|}{ During class } & After class \\
\hline \multicolumn{2}{|c|}{ M-learning methods } & \multicolumn{2}{|c|}{$\begin{array}{l}\text { Autonomous Learning } \\
\text { Personalized learning } \\
\text { collaborative learning }\end{array}$} \\
\hline \multicolumn{2}{|c|}{ M-learning resources } & \multicolumn{2}{|c|}{ Video, e-text, learning tasks } \\
\hline \multicolumn{2}{|c|}{ M-learning theory } & \multicolumn{2}{|c|}{$\begin{array}{l}\text { Humanism Learning Theory } \\
\text { Mastery Learning Theory } \\
\text { Ubiquitous Learning Theory }\end{array}$} \\
\hline \multicolumn{2}{|c|}{ M-learning device } & \multicolumn{2}{|c|}{ mobile phone, iPad, laptop } \\
\hline \multicolumn{2}{|c|}{ M-learning environment } & \multicolumn{2}{|c|}{ WiFi access, 3G / 4G access } \\
\hline
\end{tabular}

Figure 1. Mobile learning model in flipped classroom

Task-based Learning before Class. Students watch video and carry the targeted practice based electronic teaching plan by mobile devices. In the flipped classroom, the simple process of knowledge transfer is completed before class. The electronic teaching plan based on the teaching video is an important carrier of knowledge, and teachers can adjust the teaching video in time according to the different situations of students. Teachers and students communicate with each other online.

Reporting and Communication During Class. Learning activities in flipped classroom includes group reporting, interactive communication and summary evaluation of three aspects. Report links is a group of representative share learning outcomes forms; interactive communication link relates to the exchange group, group interaction between answering and teachers focus on answering; evaluation link is the summary and evaluation of the learning process, including the evaluation inside the group, group evaluation and teacher evaluation.

Consolidation and Expansion After Class. After class, teachers can collect and organize the dynamic generation resources, students' works, teachers' courseware and related development resources in the classroom. These resources can be preserved for a long time, the class did not fully grasp the content of learners through classroom teaching resources continue to learn, learn she force learners can more in-depth study by expanding resources. In addition, the learners also need to complete the online work or practice, as required, to consolidate the content.

The Design of Mobile Learning Platform in Flipped Classroom. Mobile learning platform support for three types of user roles, namely, students, teachers and administrators from the business needs. The overall design of the platform is shown in fig.2. Students in the system is the main user groups, and teachers are mainly responsible for uploading teaching resources and communication with students, administrators are mainly responsible for the maintenance of the background, data audit. 


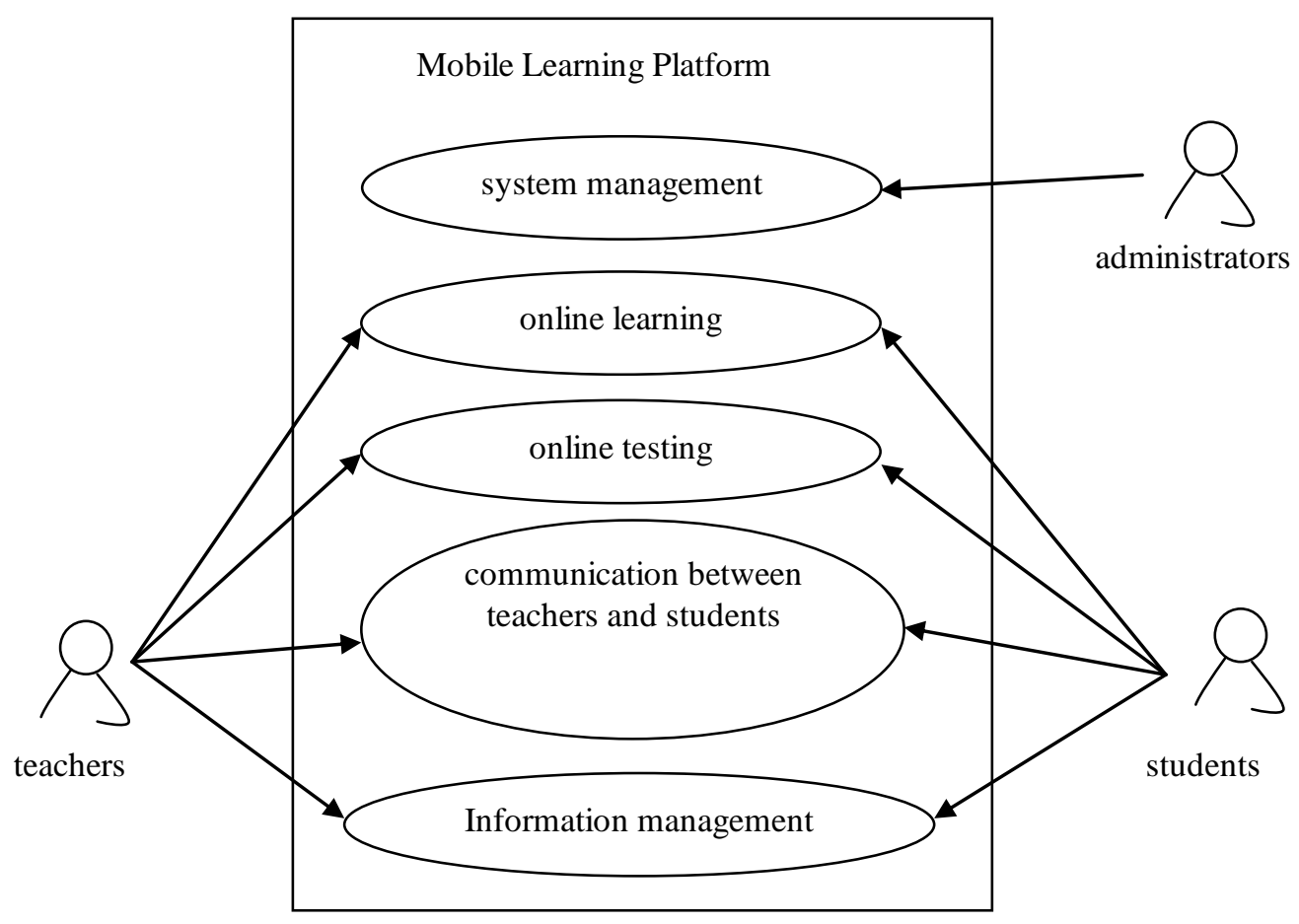

Figure 2. mobile learning platform in flipped classroom

Students: mainly through the mobile intelligent terminal (such as mobile phone, tablet computer etc.) login mobile learning platform for learning, online learning, online test, teacher-student communication, information management and other functions.

Teachers: the role of providing services to students, including the provision of teaching content, upload learning materials, to solve the difficult problems of students and other functions.

Administrators: be responsible for user information management, user rights management, data review and other content in the system, tend to deal with the background.

Among them, the focus is the functions of background management system, and mobile learning platform mainly includes the main modules of online learning, online test, communication between teachers and students, and also to have collection, evaluation, wrong homework collection, associated with the similar questions and other functions, and related auxiliary backstage management function.

\section{Conclusion}

The mobile learning platform in flipped classroom has a rich sharing of network learning resources, which is the main form of autonomous learning, breaking through the limitation of traditional learning. Under the guidance of teachers, students can explore the learning process, and then collect relevant information on the resource platform.

Teaching practice has also proved that learners identity for flipped classroom teaching mode is higher. The implementation of flipped classroom not only improves their learning efficiency, but also can stimulate interest in learning and help to improve their learning ability.

\section{References}

[1] Liu, Chun Li, L. N. Huang, and L. F. Tang. "The Research and Application of Micro Lecture for College Students in Mobile Learning." Journal of Cangzhou Normal University (2015).

[2] Song, Yong Sheng. "Design and Implementation of Mobile Learning Platform in Higher Vocational Colleges Based on We Chat and Micro-site." Computer Knowledge \& Technology (2016). 
[3] Jiang, Yong Sheng. "The Exploration of the Micro Video Construction in New Mobile Learning Environment." Journal of Guangdong University of Education (2014).

[4] Yu-Xia, D. U., et al. "Survey on University Students' Using Micro-video-based Learning Resources." Journal of Guangzhou Open University (2014).

[5] Hwang, Gwo Jen, C. L. Lai, and S. Y. Wang. "Seamless flipped learning: a mobile technology-enhanced flipped classroom with effective learning strategies." Journal of Computers in Education 2.4(2015):449-473.

[6] Wong, Gary K. W. A New Wave of Innovation Using Mobile Learning Analytics for Flipped Classroom. Mobile Learning Design. Springer Singapore, 2016.

[7] Fok, Wwt. "Cloud-based interactive mobile e-learning platform for Flipped Classroom implementation in the University of Hong Kong." (2016).

[8] F. Chen: The study of design the micro mobile learning resource based on wechat (MS., Liaoning Normal University, China 2014).

[9] G. J. Miao: Micro course design research of mobile learning environments (MS., Henan Normal University, China 2015).

[10] J. Bai: Research on key technology of mobile learning platform based on WeChat and Moodle (MS., Yunnan University, China 2015).

[11]M.X. Chen, J.Yang, The design of learning activities in the flipped classroom focusing on understanding, Open Education Research. Vol. 21 (2015) No.6, p.95. 